\title{
Analysis of the spectrum distribution of oscillation amplitudes of the concrete mix at shock vibration molding
}

\author{
Rashid Sharapov ${ }^{1 *}$ and Vitaly Vasiliev ${ }^{1}$ \\ ${ }^{1}$ Moscow state university of civil engineering, Yaroslavskoye shosse, 26, Moscow, Russia, 129337
}

\begin{abstract}
In the production of concrete structures widespread shaking tables of various designs. The effectiveness of vibroforming concrete items largely depends on the choice of rational modes of vibroeffect to the compacting mixture. The article discusses the propagation of a wave packet in the concrete mixture under shock and vibration molding. Studies have shown that the spectrum of a wave packet contains a large number of harmonics. The main parameter influencing the amplitude-frequency spectrum is the stiffness of elastic gaskets between mold and forming machine vibrating table. By varying the stiffness of the elastic gaskets can widely change the spectrum of the oscillations propagating in the concrete mix. Thus, it is possible to adjust the intensity of the process of vibroforming.
\end{abstract}

The theory and practice of vibratory compaction of concrete mixtures are still relevant in the production of concrete items and structures [1-3]. The main tasks in easel forming concrete items are the choice of effective modes of vibration effects and rational parameters of the shaking tables.

Unfortunately, when using standard molding conditions of existing construction vibrating equipment does not meet modern requirements. This is due to their large resource consumption over the low quality of manufactured concrete items, low operational reliability, as well as the excess of admissible norms of noise and vibration $[4,5]$.

To compact firm concrete mix B. V. Gusev [6] developed the theoretical foundations of shock and vibration technology. Staff members of his school were created and installed equipment for implementing low-frequency modes forming concrete items [1, 7]. In other works $[8,9]$, as effective modes of compaction of firm mixes it is proposed to use the socalled asymmetrical shock-free oscillations. The advantage of applying these oscillations is the absence of oscillating vibrotable with the balancing frame.

In articles $[10,11]$ described optimization of parameters of shock and vibration shaking tables for efficient modes of forming concrete items of firm concrete.

It is interest to consider the process of propagation of a wave packet in concrete mix under shock and vibration effects on the mold and explore a range of pulses, which propagate in the mixture.

*Corresponding author: ptdm_zavkaf@mail.ru 
The mold with concrete mixture is placed on the shaking table through the elastic element - the gasket. Under the influence of the vibrotable to the mold, they continue to move towards each other. With deformed gasket, the area of contact increases and the repulsive force from the mold of the vibrotable increases. Under the action of this force the relative speed between the mold and the working body decreases to zero. Then the elastic force to return mold and a working body of the shaking table in the original dynamic position.

In the absence of the gasket, the role of the elastic element performs the material from which made the working body.

Consider the effects that occur when oncoming traffic the mold and working body of the shaking table. Thus we investigate the pulse shape, its spectrum and duration of the process of collision.

It is known [12] that the magnitude of deformation of the elastic element (gasket or material of vibrotable) depends on the compressive strength and stiffness of the gasket.

The duration of impact can be determined by the formula:

$$
\tau=\Delta T=2,94 \cdot \sqrt[10]{\frac{1,22}{P_{0} \cdot \delta \cdot c^{4}}} \cdot \sqrt{M},
$$

where $P_{0}$ - compressive force that occurs between the mold and the working body with elastic contact, $\delta$ - the maximum distance (amplitude of oscillations) the mold from of in the process of their mutual motion, $\mathrm{m} ; c$ - the stiffness of the elastic element between the mold and the vibrotable, $\mathrm{N} \cdot \mathrm{m}^{-1} ; M$ - the reduced mass of the system "working body - mold with a mixture" determined by the formula:

$$
M=\frac{M_{1} \cdot M_{2}}{M_{1}+M_{2}},
$$

where $M_{1}$ is the mass of the working body, $\mathrm{kg} ; M_{2}$ - mass of the mold with concrete mix, $\mathrm{kg}$.

From (1) shows that $\tau$ little depends by gap size $\delta$ and strength $P_{0}$. Basically, this value is determined by the weight of the mold with concrete mix and the working body and the stiffness of the intermediate elastic element.

The force exerted at the moment of contact mold with a work body of the shaking table increases according to the following law [10]:

$$
P_{k}(t)=4,69 \frac{\sqrt{M P_{0} \delta}}{\Delta T} \sin \frac{\pi}{\Delta T} \cdot t,
$$

where $\Delta T$ - the moment of maximum convergence of the vibrotable and the mold with concrete mix:

$$
P_{k}(t)=0 \text { if } t>\Delta T \text {. }
$$

The convergence $y(t)$ of the mold with the working body undur elastic contact:

$$
y(t)=\left(1,25 \frac{M}{c}\right)^{0,4} \cdot v_{0}^{0,8} \sin \frac{\pi}{\Delta T} t,
$$

where $\Delta T$ - the moment of maximum convergence of the vibrotable and the mold with concrete mix:

$$
P_{k}(t)=0 \text { if } t>\Delta T
$$

It is known [13] that the spectrum of some almost periodic functions $y(t)$ is determined by the formula: 


$$
S(\omega)=\int_{-\infty}^{\infty} y(t) \cdot e^{-j \omega t} d t .
$$

Substituting (4) into (5) and made the necessary computing, we obtain the dependence for calculating the amplitude-frequency spectrum:

$$
S(\omega)=\frac{1,5\left(M P_{0} \delta\right)^{1 / 2} \cdot \cos \frac{\omega \cdot 2,94 \sqrt[10]{\frac{1,22}{P_{0} \cdot \delta \cdot c^{4}}} \sqrt{M}}{2}}{\left[1-\left(\frac{\omega \cdot 2,94 \sqrt[10]{\frac{1,22}{P_{0} \cdot \delta \cdot c^{4}} \sqrt{M}}}{\pi}\right)^{2}\right]},
$$

where $y$ - a deflection value of the element for elastic collision the mold with vibrotable, $\mathrm{m}$; $\omega_{i}-$ the $i$-th harmonic component of the spectrum, $\mathrm{s}^{-1}$.

According to the formula (6) carried out calculations of the spectral distribution of the vibration amplitudes of the mold for forming concrete items with a length of $5 \mathrm{~m}$, width 2 $\mathrm{m}$ and height $0.5 \mathrm{~m}$ of moderately firm concrete mix [10]. The calculated density $(\rho)$ of the concrete mix is $2400 \mathrm{~kg} / \mathrm{m} 3$, the scope of working body is $1.5 \mathrm{~mm}$, the main oscillation frequency of $12.5 \mathrm{~Hz}$. The calculation results are presented in table. 1 .

As can be seen from table 1, the spectrum of a wave packet under shock and vibration effect to the mold with the concrete mixture contains a large number of harmonics. The scatter of amplitudes of individual harmonics is large enough.

When forming concrete items on the shaking table is often occur uneven distribution of oscillation amplitudes along the surface of the vibrotable and impacts the mold on the frame of the table.

Studies of the movement of the mold under its free installation on the vibrotable of shaking table was carried out in [10]. It was shown that the spectrum propagating in a concrete mix of frequencies is wider than the periodic fluctuations the mold, which is rigidly attached to the shaking table. Multicomponent oscillations of the mold under its free installation on vibrotable generate in concrete mixture wide and almost continuous range of frequencies.

To determine the optimal parameters of the effects from working body of the forming machine on the system "mold -concrete mixture", let us analyze the formula (6). After appropriate transformations, it can be represented as follows:

$$
S\left(\omega_{\mathrm{i}}\right)=\frac{A_{1} \cdot \operatorname{Cos} \omega_{i} \cdot A_{2}}{\left(1-A_{3} \cdot \omega_{i}^{2}\right)},
$$

Table 1. The results of the calculation of the spectrum distribution of oscillation amplitudes of the mold.

\begin{tabular}{|c|c|c|c|}
\hline \multirow{2}{*}{ No of harmonic } & \multicolumn{2}{|c|}{ The frequency of the working body } & \multirow{2}{*}{$\boldsymbol{A}_{\boldsymbol{i}}, \mathbf{m m}$} \\
\cline { 2 - 3 } & $\boldsymbol{\omega}_{\boldsymbol{i}}, \mathbf{s}^{-\mathbf{1}}$ & $\boldsymbol{f}_{\boldsymbol{i}}, \mathbf{H z}$ & 7,64 \\
\hline 1 & 78,5 & 12,5 & 0,01 \\
\hline 2 & 157 & 25 & 0,8 \\
\hline 3 & 235,5 & 37,5 & \\
\hline
\end{tabular}




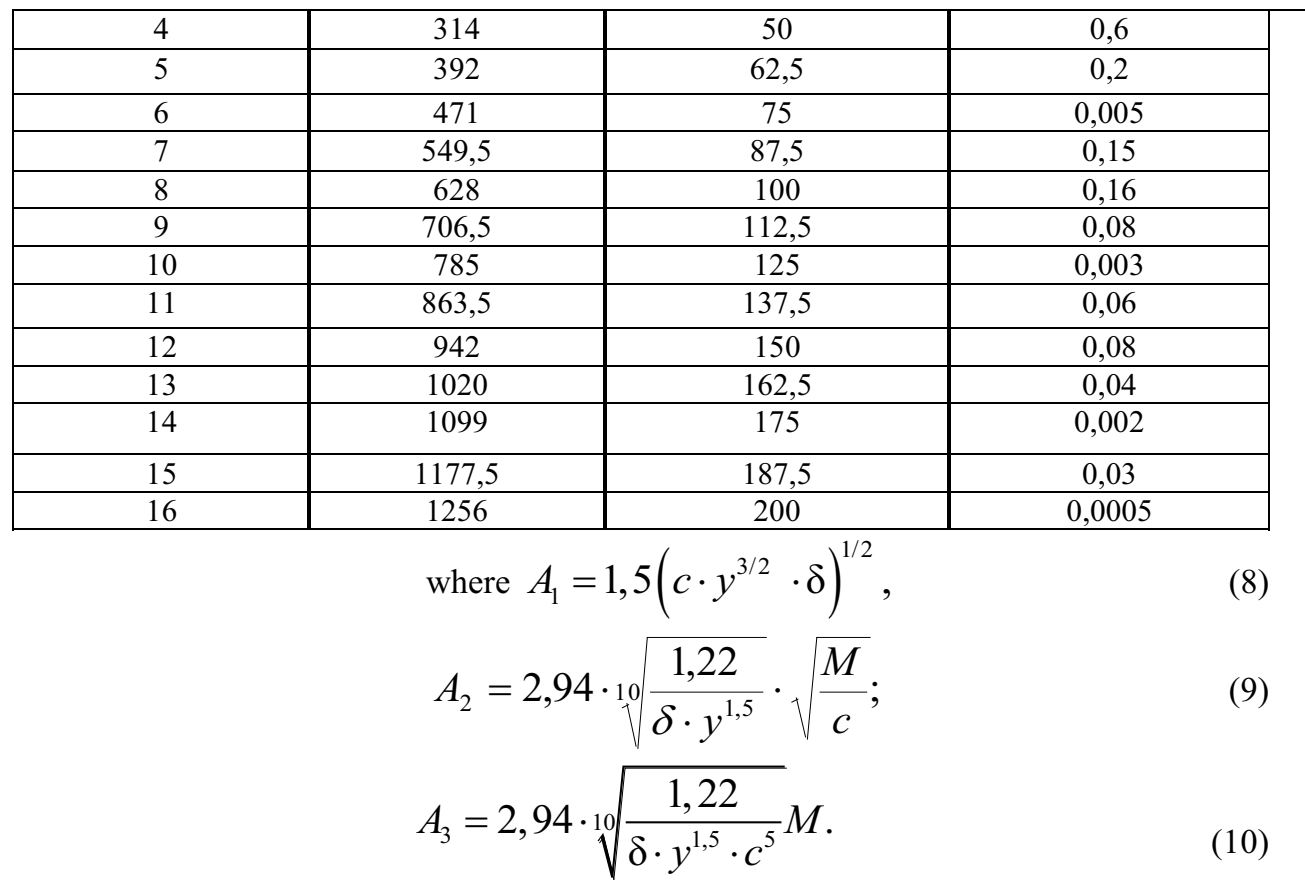

Assessing the contribution of individual components and after some simplifications, the expression (6) can be written as:

$$
\left|S\left(\omega_{i}\right)\right|=A_{1} \cdot\left|\operatorname{Cos} \omega_{i} \cdot A_{2}\right| .
$$

It is obvious that the amplitude of the spectral components will be minimal when the value $\left|\operatorname{Cos} \omega_{i} A_{2}\right|=1$, where

$$
A \cdot \omega_{i}=n \pi
$$

where $n=1,2,3, \ldots$

$$
A_{2}=\frac{n \pi}{\omega_{i}}
$$

In the transition from one spectral component to another $\left(\omega_{i . .}-\omega_{i t 1}=\omega_{t}\right)$ amplitudes of them will be maximum if:

$$
A_{2}=\frac{\pi}{\omega_{t}} \text {. }
$$

After transformation the expression (9) $A_{2}$ can be represented as follows:

$$
A_{2}=3\left(\delta \cdot y^{3 / 2}\right)^{-0,1} \cdot\left(\omega_{0}\right)^{-1}
$$

where $\omega_{0}=\sqrt{\frac{c}{M}}$ - natural frequency oscillation on an elastic element.

Substituting the expression (15) into (14) we get:

$$
\omega_{t}=\frac{\pi}{A_{2}} \cong \frac{\pi}{3} \omega_{0}\left(\delta \cdot y^{3 / 2}\right)^{0,1}=1,05 \omega_{0}\left(\delta \cdot y^{3 / 2}\right)^{0,1}
$$

In table 2 are some results of calculations of values of $\omega_{t}$ with fixed values of $\delta=7 \cdot 10^{-3} \mathrm{~m}, \mathrm{y}=0,1 \cdot 10^{-3} \mathrm{~m}$ and different values of the stiffness of the elastic gasket $c$ and the mass $M$. 
Table 2. Calculated values of the maximum amplitudes of the spectral components.

\begin{tabular}{|c|c|c|}
\hline $\begin{array}{c}\text { The stiffness of the elastic } \\
\text { gasket } \boldsymbol{c}, \mathbf{N} / \mathbf{m}\end{array}$ & Reduced mass $\boldsymbol{M}, \mathbf{k g}$ & Freguency $\boldsymbol{\omega}_{\boldsymbol{t}}, \mathbf{H z}$ \\
\hline $8 \cdot 10^{7}$ & 88,5 & 27,9 \\
\hline $6 \cdot 10^{7}$ & 76,7 & 24,5 \\
\hline $5 \cdot 10^{7}$ & 49,5 & 14,1 \\
\hline $4 \cdot 10^{7}$ & 36,1 & 11,6 \\
\hline $3 \cdot 10^{7}$ & 27,1 & 9,3 \\
\hline $2 \cdot 10^{7}$ & 19,8 & 5,2 \\
\hline $1 \cdot 10^{7}$ & 12,8 & 0,5 \\
\hline
\end{tabular}

From table 2. it follows that the stiffness of elastic contact between the mold with concrete and vibrotable significantly affects the range of vibrations which are transmitted to the concrete mixture.

For confirmation of theoretical results were carried out experimental studies of the spectrum of a wave packet in a concrete mixture using the method of holographic interferometry $[10,14]$. In the experiments we changed the elasticity of the contact, the amplitude of oscillations of the working body, the ratio of the mold mass with the concrete mixture and of the vibrotable and the frequency of the vibrodrive, which was varied in the range of $12.5 \ldots 350 \mathrm{~Hz}$. As elastic elements were used materials with a hardness in the range of $0.7 \cdot 10^{7}$ to $1.66 \cdot 10^{11} \mathrm{~N} / \mathrm{m}$.

The research program included the determination of the frequency and amplitude of the harmonic components of a wave packet spectrum and the effective acceleration of the particles of the mixture, calculated according to the formula:

$$
a=\sum_{i=1}^{n} a_{i} \cdot \omega_{i}^{2},
$$

where $a$ and $n$ are the amplitude and number of harmonics is taken.

Some results of experiments are presented in Fig.

Analysis of the research results showed that the amplitude-frequency spectrum of oscillations propagating in the concrete mix is changed according to a complicated law. For large stiffnesses of the contact between the mold and the working body of the forming machine, the distribution of amplitudes of harmonics can be seen clearly. The analysis of expression (7) shows that at large stiffnesses, high frequency harmonics, defined $\operatorname{Cos} \omega_{i}$, change little 


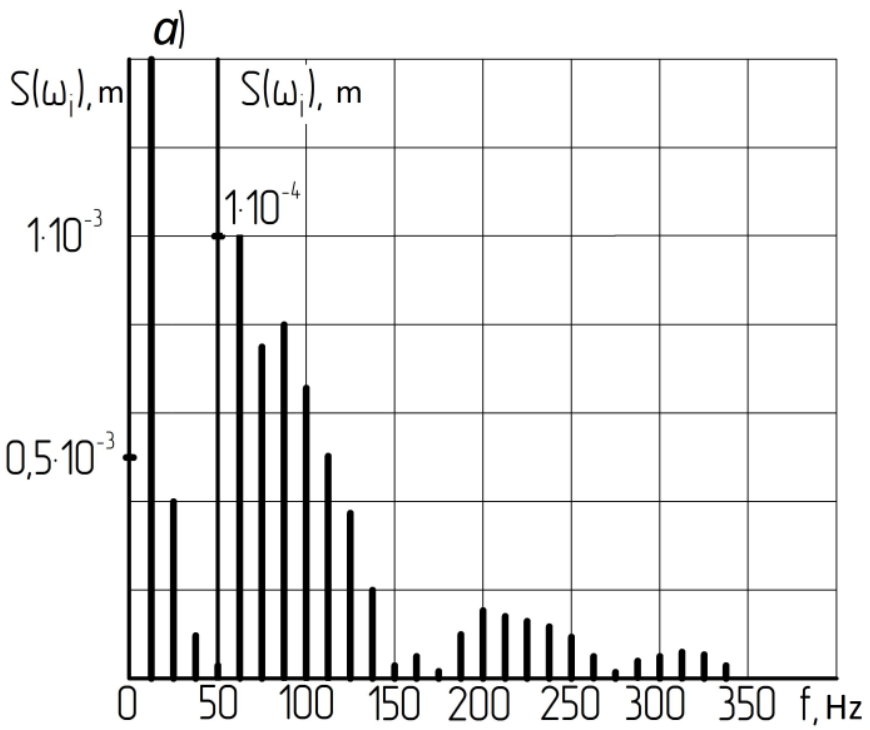

b)

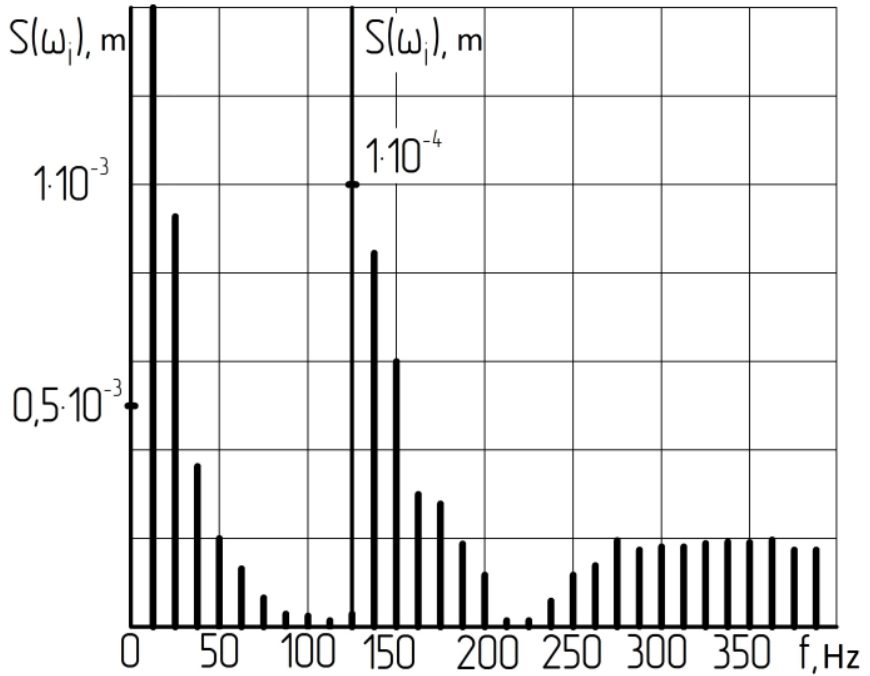

Figure. Spectra of pulses in concrete mixtures when the collision mold with vibrotable through the rubber gaskets of different hardness $\left.c: a) c=3.53 \cdot 10^{7} \mathrm{~N} / \mathrm{m} ; b\right) \mathrm{c}=2.08 \cdot 10^{7} \mathrm{~N} / \mathrm{m}$.

Under elastic contact the mold with vibrjtable through the rubber gasket with less hardness, spectra of the pulse at impact have a more complex distribution close to the law $(\operatorname{Cos} X) / X$. It has been the practical extinction of some harmonic components with increase in the amplitude of the others. Thus arise opportunities to manage spectrum by replacing one elastic gasket to another, or to use elements with adjustable stiffness $[10,15]$.

Thus, when we use the elastic gaskets with nonlinear characteristics in the system "working body - the elastic element - the mold with concrete mix" are prerequisites for substantial expansion of the spectrum generated frequencies in a mixture. Look at it from an energy point of view. The processes of vibration compaction of the concrete mix will flow more intensely when exposed to a formable mixture of a wide range of pulses. 
Moreover, the spectrum of the pulses should contain a large number of components, which carry high energy (above threshold).

As shown in $[3,10]$, for estimating the spectrum of a wave packet in the concrete mix can be successfully use such a parameter as the acceleration.

Theoretical and experimental studies have a good agreement with the results of works on creation of shaking table with controlled elastic elements $[10,15]$ and shaking table with a freely mounted the mold on the vibrotable $[16,17]$.

\section{References}

1. B.V. Gusev, V.G. Zazimko, Vibration technology of concrete. Kiev: Budivelnik, 158 p. (1991)

2. O.A.Savinov, E. V.Lavrinovich. Vibration machinery for compacting and molding concrete mixtures. L.: Stroiizdat, 278 p, (1986)

3. B.V. Gusev, E.W. Axelrod, A.I. Zvezdov, Manual on technology of forming concrete products, (to SNiP 3.09.01-85)/ M.: Stroyizdat, 111 p, (1988)

4. K.A. Olekhnovich, V.G. Zazimko, Main trends in the development of easel compacting concrete mixes, New technologies in precast concrete. M.: Znanie, pp. 9096, (1985)

5. L.A.Volkov, S.A. Genkin, V.F. Lapeev, Universal vibro-impact pad with multicomponent oscillations, Building materials, 5, pp 6-7, (1996)

6. B.V. Gusev, The theory and practice of compaction of concrete mixtures at the low frequency vibration modes, Authoref. doctor. dis. of doctor technical sciences, M.: 25 $\mathrm{p},(1977)$

7. R.R. Sharapov, A.M. Agarkov, Rinat R. Sharapov, Matrix Modeling of Technological Systems Grinding with Closed Circuit Ball Mill, World Applied Sciences Journal, 24, No. 10, pp. 1399-1403, (2013)

8. V.G. Vasiliev, F.N. Anatolly, T.A. Rakishev, Effective regimes for creation of the equipment for compaction of concrete mixtures: Chelyabinsk, pp. 18-20, (1991)

9. V.G. Vasiliev, E.G. Zinoviev, Development and investigation of asymmetric unstressed shaking table, MGAKHIS, M., 15 p, (1999)

10. E.G. Zinoviev, Shaping large size concrete products with the use of guided modes of vibration compaction: Authoref. Cand. Dis. of tech. Sciences, M., 25 p, (1989)

11. V.G. Vasiliev, The choice of optimal parameters of shock-vibrating tables, Mechanization of construction, 11, pp. 30-33, (2015)

12. V.E. Karamzin, Some features of the behavior of the concrete mix at the easel vibration, Vibration technology of concrete products, M:, Stroyizdat, pp. 67-84, (1970)

13. I.V. Shrubchenko, A.V. Hurtasenko, R.R. Sharapov, T.A. Duyun, N.A. Shchetinin, Investigation of Characteristics of Contact Bandages and Support Rollers of Rotating Technological Drums, Modern Applied Science, 9, No 1, pp. 195-203, (2015)

14. E.G. Zinoviev, V.G.Vasiliev, E.P. Parfenov, Development of methods of investigating the system "machine - environment" with the implementation of the various oscillations, MGAKHIS, M., 12 p, (1999)

15. E.G. Zinoviev, V.G.Vasiliev, V.A. Serov, Shaking table with adjustable parameters, MGAKHIS, M., 10 p. (2001)

16. S.A. Genkin, V.F. Lipeev, E.V. Parkhaev, Patent No 2002615, Russian Federation, Shaking table for compaction of the concrete mix in the mold

17. A.V. Ovchinnikov, V.N. Baryshnikov, L.A. Volkov, A.G. Pyzhikov, Patent No. 2252137, Russian Federation, Shaking table 